University of Wollongong

Research Online

Australian Institute for Innovative Materials -

Papers

Australian Institute for Innovative Materials

$1-1-2018$

Investigation of S-shaped current-voltage characteristics in highperformance solution-processed small molecule bulk heterojunction solar cells

Ali Aghassi

University of Wollongong, aa009@uowmail.edu.au

Cormac Fay

University of Wollongong, cfay@uow.edu.au

Attila J. Mozer

University of Wollongong, attila@uow.edu.au

Follow this and additional works at: https://ro.uow.edu.au/aiimpapers

Part of the Engineering Commons, and the Physical Sciences and Mathematics Commons

Research Online is the open access institutional repository for the University of Wollongong. For further information contact the UOW Library: research-pubs@uow.edu.au 


\title{
Investigation of S-shaped current-voltage characteristics in high-performance solution-processed small molecule bulk heterojunction solar cells
}

\author{
Abstract \\ The appearance of an S-shaped current-voltage curve and its impact on the performance of solution- \\ processed small molecule p-DTS(FBTTh2)2:PC70BM bulk heterojunction solar cell devices were \\ investigated. The power conversion efficiency of the devices showing S-curve characteristics was almost \\ half of what was expected for this combination of materials, which was due to a low fill factor (FF) and \\ $20 \%$ lower short circuit current density. A normal diode-like current-voltage curve was retrieved when the \\ PCBM content of the active layer was increased, with power conversion efficiency reaching $6 \%$. Analysis \\ of the current-voltage characteristics of the S-curve solar cell devices showed that the effective voltage of \\ the devices throughout the active layer was diminished due to an energy barrier. As a result, the charge \\ collection efficiency was significantly affected. In addition, smaller external quantum efficiency (EQE) \\ values in the absorption range of the small molecule donor in the S-curve devices suggested that charge \\ generation was also affected. Recombination dynamics of both the normal and S-curve devices under \\ steady-state conditions were quite similar. However, photovoltage decay results showed a distinguished \\ pattern of recombination at open circuit conditions in the S-curve devices. This suggested different \\ recombination rates at the cathode and anode electrodes, which is possibly due to the different \\ composition of the donor-acceptor film near the contacts. \\ Disciplines \\ Engineering | Physical Sciences and Mathematics

\section{Publication Details} \\ Aghassi, A., Fay, C. D. \& Mozer, A. (2018). Investigation of S-shaped current-voltage characteristics in high- \\ performance solution-processed small molecule bulk heterojunction solar cells. Organic Electronics: \\ physics, materials, applications, 62 133-141.
}

This journal article is available at Research Online: https://ro.uow.edu.au/aiimpapers/3264 


\section{Investigation of S-Shaped Current-Voltage}

Characteristics in High-Performance Solution-

Processed Small Molecule Bulk Heterojunction Solar

\section{Cells}

Ali Aghassi*, Cormac D. Fay, Attila Mozer

Intelligent Polymer Research Institute, AIIM Faculty, University of Wollongong, Innovation Campus, Wollongong, NSW 2522, Australia.

\section{Corresponding Author}

*E-mail: aa009@uowmail.edu.au (Ali Aghassi, Ph.D.)

Keywords: solution-processed small molecule, S-curve, time-resolved charge extraction, bimolecular recombination, light-intensity dependency. 


\begin{abstract}
The appearance of an S-shaped current-voltage curve and its impact on the performance of solution-processed small molecule p-DTS(FBTTh $)_{2}: \mathrm{PC}_{70} \mathrm{BM}$ bulk heterojunction solar cell devices were investigated. The power conversion efficiency of the devices showing S-curve characteristics was almost half of what was expected for this combination of materials, which was due to a low fill factor (FF) and $20 \%$ lower short-circuit current density. A normal diode-like current-voltage curve was retrieved when the PCBM content of the active layer was increased, with power conversion efficiency reaching $6 \%$. Analysis of the current-voltage characteristics of the S-curve solar cell devices showed that the effective voltage of the devices throughout the active layer was diminished due to an energy barrier. As a result, the charge collection efficiency was significantly affected. In addition, smaller external quantum efficiency (EQE) values in the absorption range of the small molecule donor in the S-curve devices suggested that charge generation was also affected. Recombination dynamics of both the normal and S-curve devices under steady-state conditions were quite similar. However, photovoltage decay results showed a distinguished pattern of recombination at open circuit conditions in the S-curve devices. This suggested different recombination rates at the cathode and anode electrodes, which is possibly due to the different composition of the donor-acceptor film near the contacts.
\end{abstract}




\section{Introduction}

Bulk heterojunction (BHJ) solar cells have been the subject of extensive research over the past decade due to their potential of producing cost-effective clean energy. These devices are composed of a bicontinuous interpenetrating network of electron-donating and electron-accepting materials which are sandwiched between cathode and anode electrodes [1]. Recently, bulk heterojunction solar cells based on the solution-processed small molecule (SM, donor) and fullerene derivatives (acceptor) have attracted much attention due to their potential to compete with traditional conjugated polymer-based solar cells [2, 3]. Some of their advantages over polymeric counterparts include: monodispersity, simple synthesis and purification, reproducibility from batch-to-batch, a relatively high mobility [3-5]. Enhancement of power conversion efficiency in SM BHJ solar cells is mostly achieved through new molecular frameworks[6-9], engineering bulk heterojunction morphology [10-13], and interface modification between the bulk and the electrodes [14].

Morphological characteristics of the bulk heterojunction in SM based solar cells significantly influence the generation and extraction of charge carriers. Achieving an optimized morphology is a compromise between domain size and domain purity of the donor and acceptor materials within the bulk film [10-12]. Domain size influences charge carriers generation and domain purity may be important for uninterrupted paths for charge carriers collection at the electrodes. Consequently, any morphological deformation within the bulk or at the electrode contact could potentially result in poor performance. One of these defects is the appearance of an S-shaped characteristic in the fourth quadrant of the current-voltage curve, i.e. the power output region of the solar cells. The socalled "kink" is usually associated with significant reduction of fill factor (FF) and power conversion efficiency (PCE). Several origins of the S-shaped current-voltage curve in polymer 
solar cells have been suggested in the literature, which include: vertical phase separation $[15,16]$, defect or surface dipoles at the interface [17-19], energy barrier [20-22], and imbalanced charge mobility [23]. A few models have also been proposed to address the physical mechanism for the appearance of an S-curve [19, 24-27]. Dyakonov et al. [26] developed a numerical model and introduced reduced surface recombination velocity of the majority carriers to explain the S-shaped current-voltage curve. Yang et al. [19] suggested that the formation of a dipole is responsible for the kink in the current-voltage curve. Both models focused on the interface between the active layer and ITO electrode. Schwartz et al. [24] described a model based on the vertical phase separation of the active layer, suggesting that the mismatch in electron and hole mobility in conjunction with an abrupt change in the mobility at the interface can lead to the appearance of an S-shaped curve. While there are several reports investigating the appearance of an S-shaped current-voltage curve in polymer donor based bulk heterojunction solar cells, those studies concerning the origin of an S-shaped current-voltage curve in the solution-processed small molecules are limited [28].

In this study, the S-shaped current-voltage characteristics in a bulk heterojunction solar cells composed of 7,7'-(4,4-bis(2-ethylhexyl)-4H-silolo[3,2-b:4,5-b']dithiophene-2,6-diyl)bis(6-fluoro4-(5'-hexyl-[2,2'-bithiophen]-5-yl) benzo[c][1,2,5] thiadiazole) and [6,6]-phenyl C70 butyric acid methyl ester $\left.(p \text {-DTS(FBTTh })_{2}: \mathrm{PC}_{70} \mathrm{BM}\right)$ is investigated. As demonstrated here, the S-shaped current-voltage curve is correlated with the ratio of the SM donor and acceptor in the active layer. While devices with a higher portion of the small molecule relative to $\mathrm{PC}_{70} \mathrm{BM}$ (donor-rich device, DR) often show an S-curve, it is found that increasing the ratio of the acceptor in the bulk heterojunction (acceptor-rich device, AR) give rises to a normal diode-like behavior. External quantum efficiency and UV-Vis absorption measurements reveal lower charge photo-generation 
in the DR devices contributing to $20 \%$ lower short-circuit current density. To understand the origin of the S-curve behavior and low FF, the photocurrent density-voltage curves are analyzed and photo-induced charge carrier generation rate $\left(G_{\max }\right)$ and the charge collection probability $\left(P_{c}\right)$ are calculated and compared. This analysis suggests the presence of an extraction barrier in the DR devices. The surface morphology of the films is investigated using atomic force microscopy showing increased domain size and surface roughness in the DR devices. Electron lifetime and charge mobility are also compared employing a variety of steady-state and transient techniques. It is concluded that the main effect for the lower performance for the DR devices is the diminished charge extraction efficiency due to the lower internal electric field in the active layer. 


\section{Material and Methods}

2.1. Materials: Small molecule $p$-DTS(FBTTh $)_{2}$ was purchased from 1-Material and used as received. Anhydrous chlorobenzene and 1,8-diiodooctane (DIO) were bought from SigmaAldrich. $\mathrm{PC}_{70} \mathrm{BM}$ was purchased from Solaris Chem Inc. (Quebec, Canada) and used without further purification. Poly(3,4-ethylenedioxythiophene)-poly(styrenesulfonate) solution (PEDOT:PSS) (Clevios ${ }^{T M}$ P VP AI4083) was supplied by "Heraeus Deutschland GmbH \& Co.” and kept in the dark and under ambient temperature and pressure. Pre-patterned indium tin oxide (ITO) coated glasses (Rs $\left.\leq 15 \Omega \mathrm{sq}^{-1}\right)$ were purchased from Xin Yan Technology LTD.

2.2. Device fabrication: Blend solutions of $p$-DTS $\left(\mathrm{FBTTh}_{2}\right)_{2}: \mathrm{PC}_{70} \mathrm{BM}$ were prepared at four different weight ratios, namely, 1.5:1 (donor-rich, DR), 1:1, 1:1.5 (acceptor-rich, AR) and 1:2 in chlorobenzene with $0.4 \%(\mathrm{v} / \mathrm{v})$ of DIO processing additive. The total concentration of the solutions was $35 \mathrm{mg} / \mathrm{ml}$. The structure of the solar cell devices was ITO/PEDOT:PSS/pDTS(FBTTh $)_{2}: \mathrm{PC}_{70} \mathrm{BM} / \mathrm{Al}$. ITO-coated glass substrates were cleaned sequentially by sonication in deionized (DI) water, acetone and isopropanol and then treated with UV ozone for 20 minutes. The hole transport material, PEDOT:PSS, was spin-casted at $5000 \mathrm{rpm}$ for $45 \mathrm{~s}$ in order to obtain a thickness of $30 \sim 40 \mathrm{~nm}$. The substrates were then annealed for $10 \mathrm{~min}$ at $150{ }^{\circ} \mathrm{C}$. Photoactive materials were cast from the donor-rich solutions at $2000 \mathrm{rpm}$ for $45 \mathrm{~s}$ and acceptor-rich solutions at $1000 \mathrm{rpm}$ for $45 \mathrm{~s}$ (the $1: 1$ ratio photoactive solution was cast at $1800 \mathrm{rpm}$ for $45 \mathrm{~s}$ and the $1: 2$ ratio active material solution was cast at $800 \mathrm{rpm}$ for $45 \mathrm{~s}$ ). The final thickness of the BHJ film for both acceptor-rich and donor-rich was measured to be $100 \pm 5 \mathrm{~nm}$ (Figure S2, Supplementary Information), determined by a stylus surface profiler (Dektak 150, Veeco). The films were allowed to dry inside glovebox for $30 \mathrm{~min}$ and then were heated to $70{ }^{\circ} \mathrm{C}$ for $10 \mathrm{~min}$ and $80{ }^{\circ} \mathrm{C}$ for $5 \mathrm{~min}$ to evaporate the residual solvent. Finally, the cathode was deposited by thermal evaporation of 100 
$\mathrm{nm}$ of aluminum. The active area of the cell was $0.06 \mathrm{~cm}^{2}$. Devices were fabricated in the air and then transferred to an argon-filled glovebox for glass encapsulation.

2.3. Film characterization: The surface morphology of the BHJ films were investigated by AFM (Asylum Research, MFP-3D) in tapping mode. Sample BHJ films for AFM measurement were prepared on the top of PEDOT:PSS coated ITO. UV-Vis absorption of the BHJ films was recorded using a UV-VIS-NIR spectrophotometer (Shimadzu, UV-3600). The films were cast on a microscope glass slide for absorption measurement. The baseline was corrected for glass absorption using a single point correction at $800 \mathrm{~nm}$.

2.4. Current-Voltage measurement: The current-voltage characteristics of the solar cells were measured using a simulated $100 \mathrm{~mW} \mathrm{~cm}^{-2}$ Air Mass (AM) 1.5G white light illumination provided by a solar simulator (PV Measurement Inc.) and a Keithley 2400 source meter unit. The irradiance was calibrated with a standard silicon photovoltaics certified by National Renewable Energy Laboratory. All encapsulated solar cells were tested in ambient air.

2.5. Incident photon-to-current efficiency (IPCE): External quantum efficiency was measured using a QEX10 quantum efficiency measurement system (PV Measurement Inc.). AC mode was chosen for both calibration and measurement. A $10 \mathrm{~nm}$ wavelength step was set to record the photocurrent response of the device.

2.6. Time-resolved charge extraction (TRCE): TRCE measurement was performed using a nanosecond switch (Asama Lab.). The role of the switch was to retain the device at open circuit conditions (2.2 Mohm impedance) for a well-defined, adjustable delay time after charge generation by a laser pulse $(10 \mu \mathrm{j}, 532 \mathrm{~nm}$, and repetition rate $10 \mathrm{~Hz})$. When the impedance was switched to low, i.e. triggered by a digital delay generator (Stanford research DG 535), the extraction of photogenerated charges takes place. The resulting transient photocurrent was recorded by a digital 
oscilloscope (Tektronix, DPO4054). Integration of the photocurrent transient yielded the amount of charge. Charge density was calculated by dividing the amount of charge by the volume of the active layer. The charge associated with the switch dark capacitive response was subtracted to obtain a photo-generated charge density.

2.7. Photovoltage decay (PVD): The device was held at open circuit conditions (1 M $\Omega$ internal impedance of the oscilloscope) and illuminated by the laser pulse. The decay of photo-generated voltage was then monitored over time. 


\section{Results}

\subsection{Device Performance and UV-Vis Absorption}

The device architecture and chemical structure of the small molecule $p$-DTS(FBTTh $)_{2}$ and $\mathrm{PC}_{70} \mathrm{BM}$ are shown in Figure 1. The architecture was comprised of indium tin oxide (ITO) / poly(3,4-ethylenedioxythiophene) poly(styrenesulfonate) (PEDOT:PSS)/pDTS(FBTTh $)_{2}: \mathrm{PC}_{70} \mathrm{BM} /$ aluminum (Al). The highest occupied molecular orbital (HOMO) and the lowest unoccupied molecular orbital (LUMO) energy levels of small molecule $p$ DTS(FBTTh $)_{2}$ and $\mathrm{PC}_{70} \mathrm{BM}$ are depicted in Figure 1c. The average photovoltaic parameters (eight identically prepared devices) of the solar cell devices fabricated with 1.5:1, 1:1, 1:1.5 and 1:2 donor:acceptor weight ratio of $p$-DTS(FBTTh $)_{2}: \mathrm{PC}_{70} \mathrm{BM}$ are summarized in Table 1.

(a)

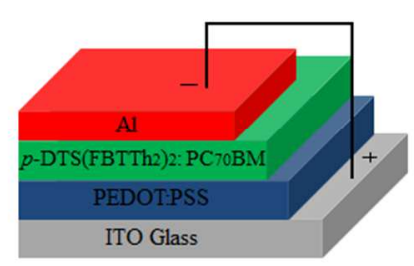

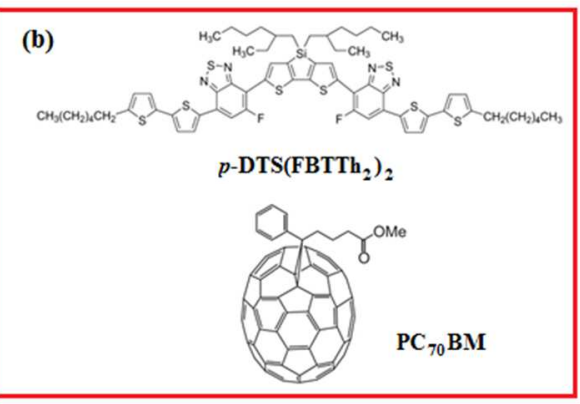

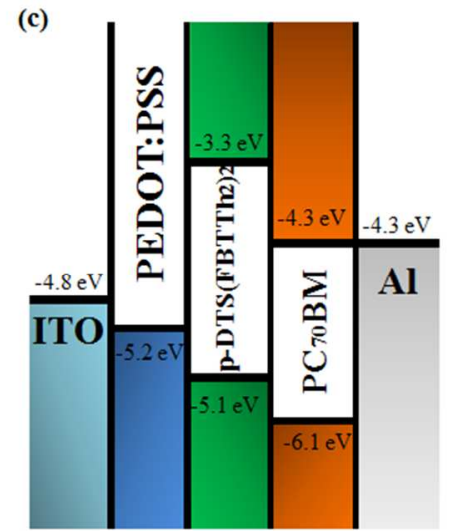

Figure 1. (a) Schematic of device architecture. (b) Molecular structures of $p$-DTS(FBTTh $)_{2}$ and $\mathrm{PC}_{70} \mathrm{BM}$. (c) Energy level diagram of SM bulk heterojunction solar cell comprised of ITO/PEDOT:PSS/p-DTS(FBTTh $)_{2}: \mathrm{PC}_{70} \mathrm{BM} / \mathrm{Al}$ cathode. The HOMO and LUMO levels of $p$ DTS $\left(\mathrm{FBTTh}_{2}\right)_{2}$ and $\mathrm{PC}_{70} \mathrm{BM}$ were obtained from ref $[13,14]$. 
Table 1. Photovoltaic parameters of $p$-DTS(FBTTh $)_{2}: \mathrm{PC}_{70} \mathrm{BM}$ solar cell device with different weight ratio of donor and acceptor

\begin{tabular}{ccccc}
\hline Donor:Acceptor ratio & $\mathbf{V}_{\text {oc }}(\boldsymbol{V})$ & $\mathbf{J}_{\mathbf{s c}}\left(\boldsymbol{m A} \mathbf{c m}^{-2}\right)$ & $\mathbf{F F}$ & PCE (\%) \\
\hline $\mathbf{1 . 5}: \mathbf{1}$ & $0.78 \pm 0.025$ & $11.1 \pm 0.75$ & $0.39 \pm 0.03$ & $3.29 \pm 0.27$ \\
\hline $\mathbf{1}: \mathbf{1}$ & $0.735 \pm 0.09$ & $11.8 \pm 0.39$ & $0.44 \pm 0.03$ & $3.85 \pm 0.4$ \\
\hline $\mathbf{1}: \mathbf{1 . 5}$ & $0.74 \pm 0.12$ & $13.97 \pm 0.4$ & $0.56 \pm 0.04$ & $5.95 \pm 0.2$ \\
\hline $\mathbf{1 : 2}$ & $0.743 \pm 0.06$ & $12.7 \pm 0.4$ & $0.55 \pm 0.01$ & $5.2 \pm 0.2$ \\
\hline
\end{tabular}

It is observed that devices composed of 1.5:1 (Figure 2a (red curve)) and 1:1 (Figure S1a, Supplementary Information) weight ratio of donor to acceptor show S-shaped current densityvoltage characteristics, whereas devices with higher content of the acceptor show normal diodelike current-voltage curve (Figure 2a (black curve) and Figure S1b, Supplementary Information). It is clear that the S-shaped current-voltage curve originates from bulk heterojunction and is diminished when the donor/acceptor ratio was altered. It was found that a ratio of 1:1.5 D:A is critical to obtain high $F F$ and $J_{s c}$ (Figure 2a). The 1:2 ratio devices also show normal current density-voltage curve, but lower performance compared to the 1:1.5 device due to lower $J_{s c}$ (Figure S1b, Supplementary Information). Moreover, the devices fabricated with 1:1 D/A weight exhibit the S-shaped current-voltage curve, although slightly less pronounced as indicated by the higher FF (0.44). Hence, the SM BHJs devices using 1.5:1 (donor-rich, DR) and 1:1.5 (acceptor rich, $\mathrm{AR}$ ) weight ratio of the small molecule to $\mathrm{PC}_{70} \mathrm{BM}$ were chosen for the further investigation. The current density-voltage characteristics of the solar cell devices consisting of donor-rich and acceptor-rich active layers measured under $100 \mathrm{~mW} \mathrm{~cm}^{-2}$ calibrated white light and in the dark are compared in Figure 2a. The current-voltage curves for the highest efficiency devices are presented. 
It can be seen from Table 1 that the power conversion efficiency of solar cells consisting of acceptor-rich active layers $(6 \%)$ is almost twice as large as those consisting of donor-rich active layers $(3.29 \%)$. In terms of the current-voltage profile of each device, it can be seen that the solar cells using DR active layers show an S-shape in the fourth quadrant, whereas the AR devices show normal diode behavior. While the open circuit voltage $\left(V_{o c}\right)$ of the DR devices is slightly higher, the fill factor of the DR devices is $31 \%$ lower (0.39) in comparison to AR devices, which is the main reason for their lower performance. Additionally, the short circuit current density of the DR devices is $20 \%$ lower $\left(11.1 \mathrm{~mA} \mathrm{~cm}^{-2}\right)$, which further contributes to their lower efficiency. Moreover, the forward bias injection current onset potential for the DR device is shifted by $0.5 \mathrm{~V}$ to higher potentials both in the dark and under illumination.

Figure $2 \mathrm{~b}$ shows UV-Vis absorption spectra of the donor- and acceptor-rich $p$ $\mathrm{DTS}\left(\mathrm{FBTTh}_{2}\right)_{2}: \mathrm{PC}_{70} \mathrm{BM}$ active layer films. The absolute values of the absorbance are in the range of 0.25 to 0.6 depending on the wavelength. Both spectra show two absorption features at $383 \mathrm{~nm}$ and 550 to $770 \mathrm{~nm}$. This matches the reported absorption spectrum of the donor $p$-DTS(FBTTh $)_{2}$ contribution from $\mathrm{PC}_{70} \mathrm{BM}$ absorption at $400 \mathrm{~nm}$. By increasing the acceptor ratio content, the relative strength of absorbance is decreased with the $550 \mathrm{~nm}$ to $700 \mathrm{~nm}$ wavelength range. 

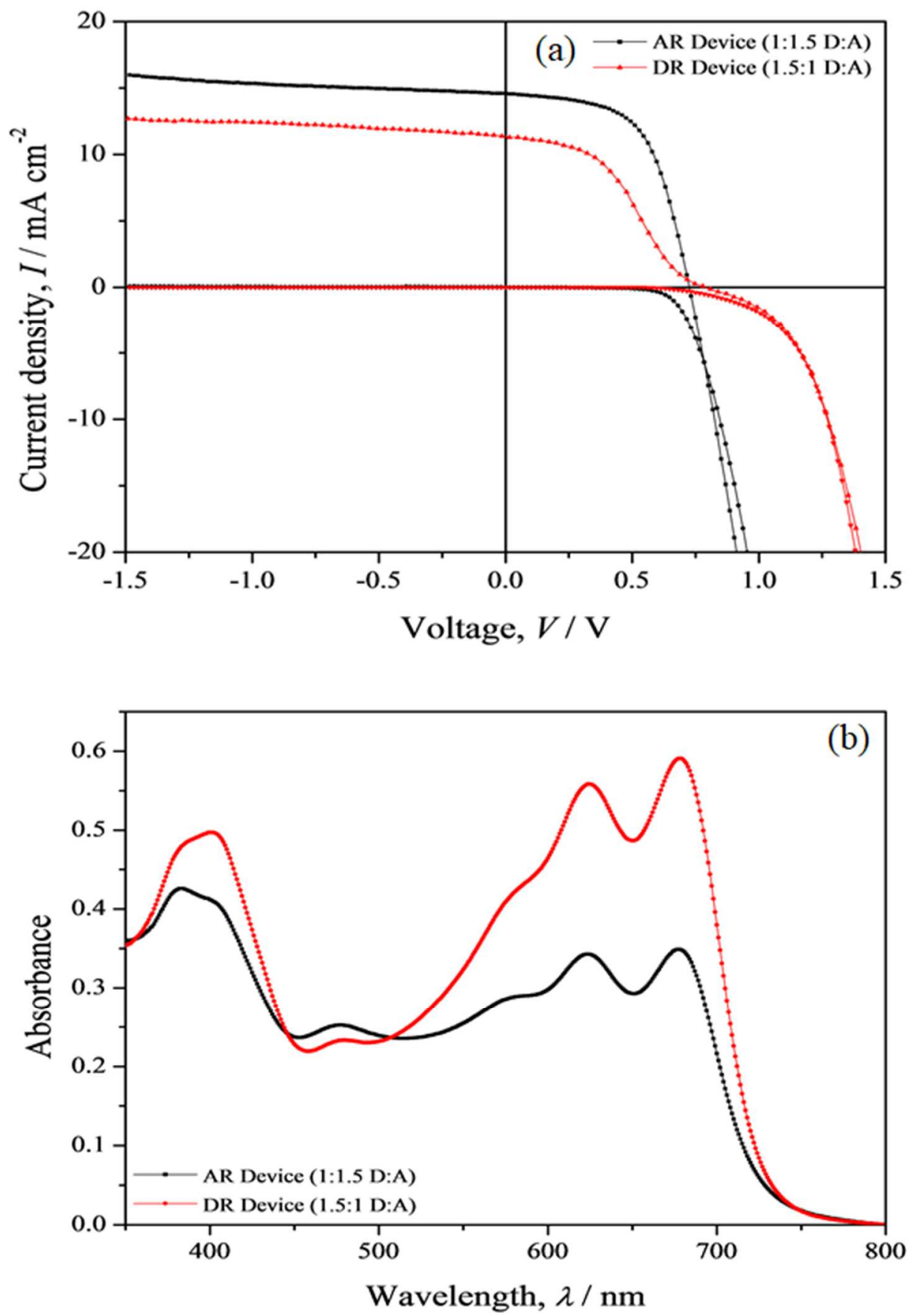

Figure 2. (a) Current density-voltage characteristics of solar cell devices composed of $p$ DTS(FBTTh $)_{2}: \mathrm{PC}_{70} \mathrm{BM}$ bulk heterojunction film with $1.5: 1$ (DR device, red) and $1: 1.5$ (AR device, black) weight ratio of Donor : Acceptor (b) UV-vis absorption spectra of the photoactive layers. 


\subsection{EQE and Charge Generation and Collection}

External quantum efficiency (EQE) of the solar cell devices is shown in Figure 3a. Despite the enhanced light absorption by the DR active layer within the $550 \mathrm{~nm}$ to $700 \mathrm{~nm}$ wavelength range, the EQE values were found to be lower when compared to the AR devices by up to $10 \%$. The lower EQE values suggest lower charge separation and/or collection in the DR type devices. The $J_{s c}$ values were calculated from the EQE spectrum by integrating with a standard AM 1.5 spectrum. This resulted in $13.7 \mathrm{~mA} \mathrm{~cm}^{-2}$ and $11.8 \mathrm{~mA} \mathrm{\textrm {cm } ^ { - 2 }}$ for AR and DR devices respectively, which is consistent with $J_{s c}$ measured in Figure 2.

To analyze charge collection efficiency, Figure $3 b$ shows photocurrent density $\left(J_{p h}\right)$ as a function of effective voltage $\left(V_{\text {int }}\right)$ for both DR and AR devices, both of which were measured under $100 \mathrm{~mW} \mathrm{~cm} \mathrm{~cm}^{-2}$ illumination. $J_{p h}$ was calculated as $J_{p h}=J_{L}-J_{D}$, by subtracting the current density measured in the dark $\left(\mathrm{J}_{\mathrm{D}}\right)$ from the current density measured under illumination $\left(J_{L}\right) \cdot V_{\text {int }}$ was calculated according to $V_{i n t}=V_{B I}-V_{a p p}$ by subtracting the applied voltage $\left(V_{a p p}\right)$ from the builtin voltage $\left(V_{B I}\right)$ of the device. $V_{B I}$ refers to the voltage at which $J_{p h}$ is zero $[14,29,30]$.

In Figure $3 b, J_{p h}$ of the AR devices increases proportionally and in a linear fashion with respect to the voltage at low $V_{\text {int }}(<0.2 V)$, while saturating at high $V_{\text {int }}(<0.3 V)$, where the internal electric field is strong enough to sweep out all charge carriers. In the DR devices, the increase in $J_{p h}$ with increasing $V_{i n t}$ occurs at higher (by $0.3 V$ ) voltages. Also, note that the value of $V_{\text {int }}$ (calculated according to the above definition) is higher in the DR devices by approximately $0.2 \mathrm{~V}$ (given that the $\mathrm{V}_{\mathrm{BI}}$ value is $0.8 V$ for the AR device and $1 V$ for the DR device shown in Figure 3).

The photocurrent $J_{p h}$ can also be expressed as $[14,29,30]$

$$
\mathrm{J}_{\mathrm{ph}}=\mathrm{edG}_{\max } \mathrm{P}_{\mathrm{c}}
$$


where $e$ is elementary charge, $d$ is the thickness of the active layer, $G_{\max }$ is maximum photoinduced charge carrier generation rate per unit volume and $P_{c}$ is charge collection probability. The photocurrent reaches a plateau $\left(J_{p h, s a t}=e d G_{m a x}\right)$ at sufficiently large negative voltages when internal electric field within the device is strong enough to sweep out all charge carriers $\left(P_{c}=1\right)$. Then charge collection probability can, therefore, be determined as [14, 29, 30]:

$$
\mathrm{P}_{\mathrm{c}}=\frac{J_{p h}}{J_{\text {sat }, p h}}
$$

The $G_{m a x}$ value for the DR device was calculated as $7.811 \times 10^{21} \mathrm{~cm}^{-3} \mathrm{~s}^{-1}\left(J_{p h, s a t}=12.65 \mathrm{~mA} \mathrm{~cm}^{-2}\right)$, whereas the $G_{\max }$ value for the AR device was found to be $17 \%$ higher at $9.47 \times 10^{21} \mathrm{~cm}^{-3} \mathrm{~s}^{-1}\left(J_{p h \text {,sat }}\right.$ $\left.=15.17 \mathrm{~mA} \mathrm{~cm}^{-2}\right)$. The charge collection probability $\left(P_{c}\right)$ as a function of $V_{\text {int }}$ is shown in Figure 3c. Higher values of $P_{c}$ are calculated for the AR device across the entire range of applied voltage. At short circuit conditions (indicated by the arrows within the figure), the difference in $P_{c}$ values was smaller (0.96 vs. 0.90$)(6 \%)$. At lower internal voltage values close to $V_{o c}\left(\sim V_{\text {int }}-0.1 V\right)$, the $P_{c}$ values were one order of magnitude higher in the AR device. 

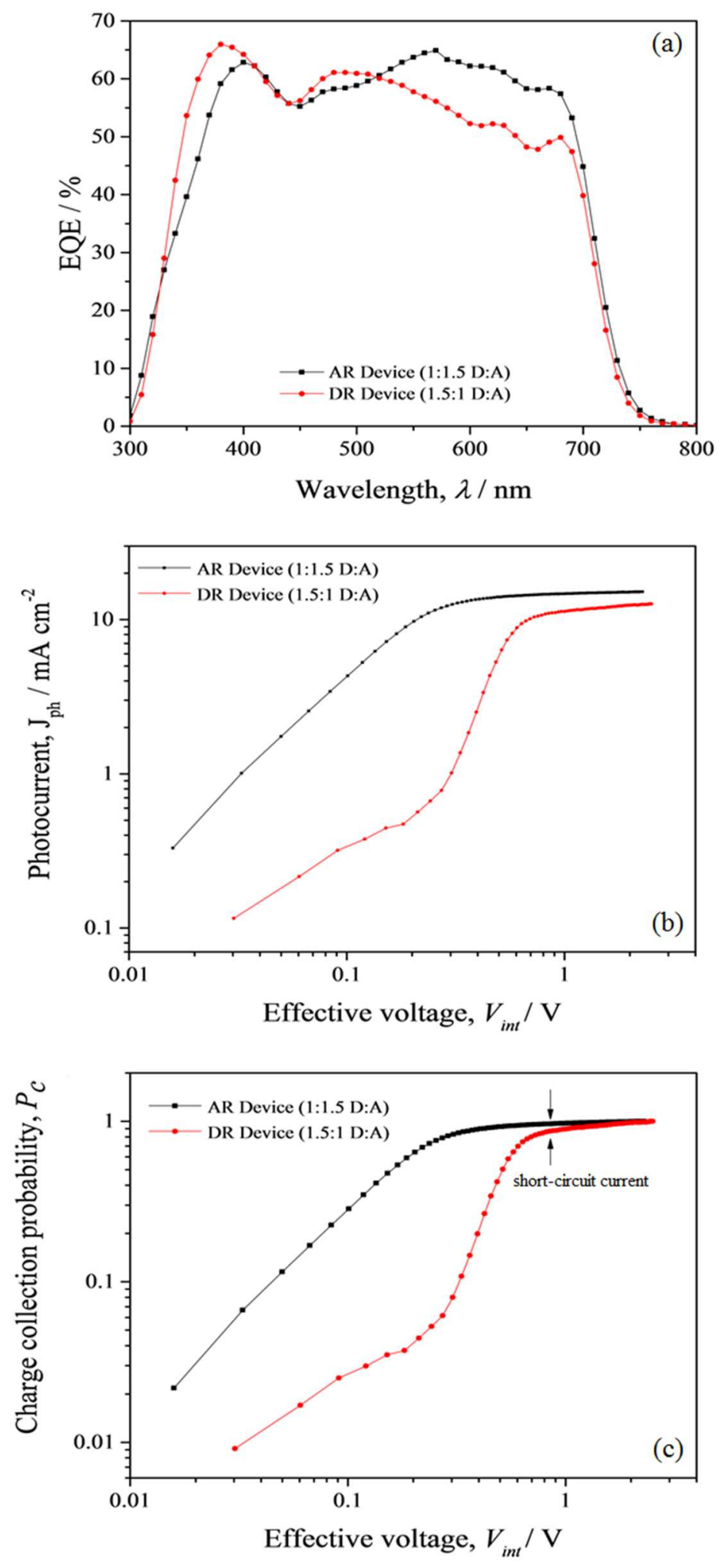

Figure 3. (a) External quantum efficiency, (b) Photocurrent density and (c) Charge collection probability $\left(\mathrm{P}_{\mathrm{c}}\right)$ as a function of effective voltage, of DR (red) and AR (black) solar cell devices. 


\subsection{Surface Morphology}

Atomic Force Microscopy (AFM) was employed to evaluate the surface morphology of the active layers upon altering the donor and acceptor ratio. Figure 4 presents AFM topographic and phase images of DR and AR films. A surface roughness of $1.73 \mathrm{~nm}$ (average of four samples) was obtained for DR film which is larger than for AR film showing smaller grain sizes and a smoother surface roughness with a root mean square (RMS) of $0.84 \mathrm{~nm}$.
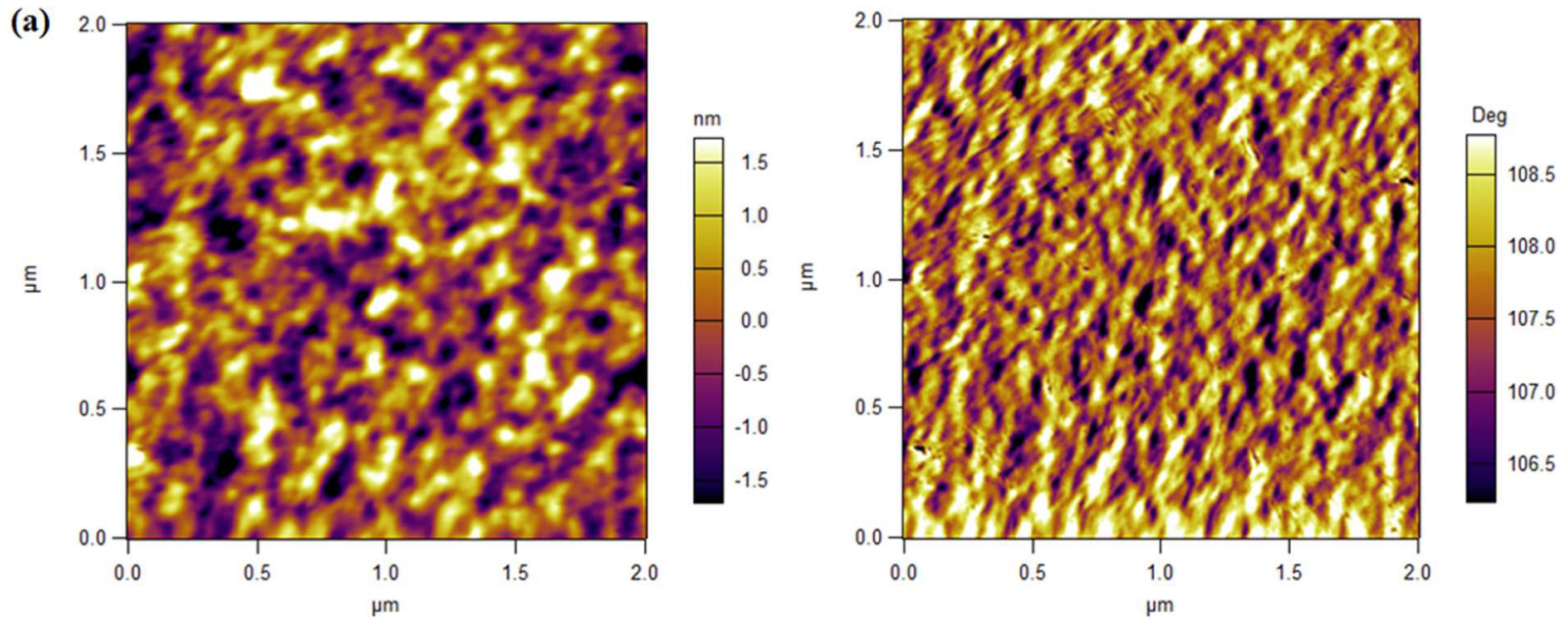

(b)
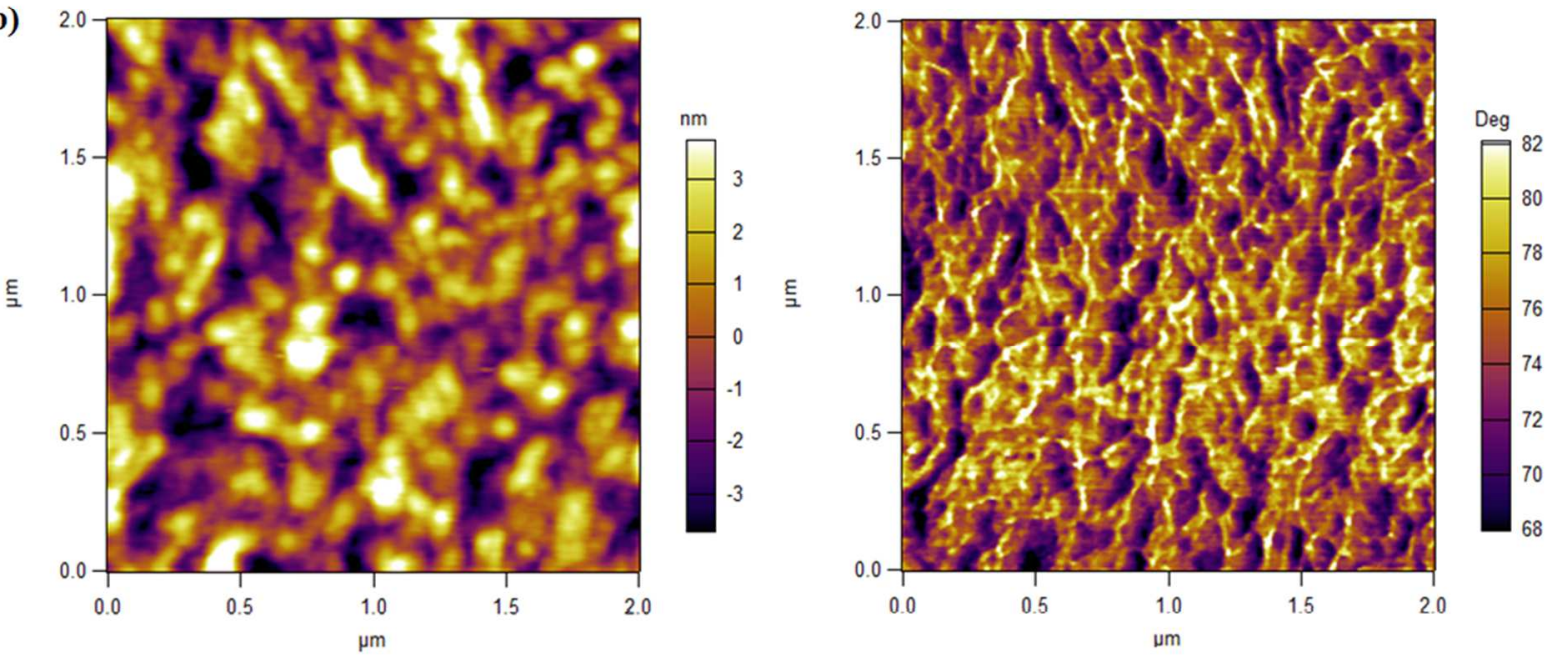

Figure 4. Tapping mode AFM topography (left) and corresponding phase images (right) of $p$ DTS(FBTTh $)_{2}: \mathrm{PC}_{70} \mathrm{BM}$ film fabricated with (a) $1: 1.5$ weight ratio of donor : acceptor (top) (b) $1.5: 1$ weight ratio of donor : acceptor (bottom), respectively. 


\subsection{Recombination dynamics under steady state conditions}

Recombination dynamics of charge carriers in donor-rich and acceptor-rich devices was investigated by analyzing the dependence of $V_{o c}$ and $J_{s c}$ on incident light intensities ranging from $100 \mathrm{~mW} \mathrm{~cm}^{-2}$ to $1 \mathrm{~mW} \mathrm{~cm}^{-2}$ (Figure 5). At short circuit conditions, due to the effective extraction of charge carriers, charge carrier density is typically low and the recombination often follows firstorder kinetics [29-31]. A power law dependency is often observed between light intensity $(I)$ and short-circuit current as:

$$
\mathrm{J}_{\mathrm{sc}} \propto \mathrm{I}^{\alpha}
$$

where $\alpha$ is close to unity when the dominant recombination is first-order. The $\alpha$ value (Figure 5a) for both $\mathrm{AR}$ and $\mathrm{DR}$ devices deviate from unity (by 0.78555 and 0.77473 , respectively). This indicates a contribution from other factors on charge carriers annihilation at short circuit conditions such as bimolecular recombination, space charge effects or charge carrier mobility imbalance [30].

At open circuit conditions, charge densities are much higher and therefore higher-order (e.g. bimolecular) recombination can be dominant, which can be inferred from studying $V_{o c}$ as a function of the light intensity $[14,29,30]$. For the pure bimolecular recombination, the predicted slope of the $V_{o c}$ versus the natural logarithm of the light intensity is $k T / e$ where $k$ is Boltzmann constant, $T$ is temperature in Kelvin, $e$ is elementary charge. In Figure $5 \mathrm{~b}$, the slope of $V_{o c}$ versus light intensity for both devices is very similar and close to kT/e implying that bimolecular recombination is the dominant mechanism at open circuit conditions. Analysis of the light intensity dependence of 4 DR devices and 4 AR devices confirms this (Table S1 and Table S2, Supplementary Information) suggesting that the recombination dynamics of the devices at steady state condition is only marginally altered between AR and DR devices. 

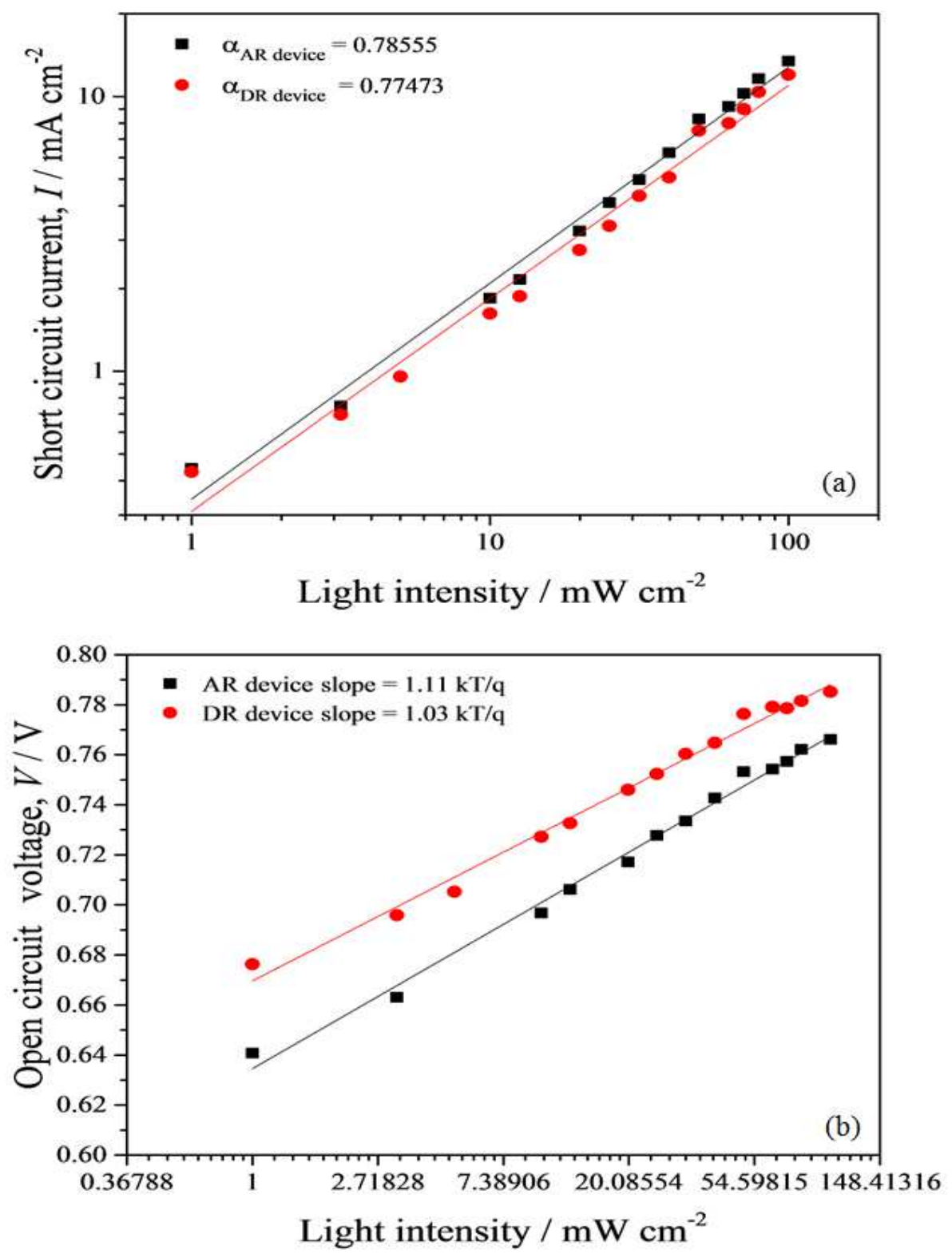

Figure 5. Measured (a) short circuit current, and (b) open circuit potential as a function of the incident light intensity (from $100 \mathrm{~mW} \mathrm{~cm} \mathrm{~m}^{-2}$ to $1 \mathrm{~mW} \mathrm{~cm}^{-2}$ ) of acceptor-rich (red) and donor-rich (black) solar cell devices. The coefficient of determination, $\mathrm{R}^{2}$, for fitting parameters are around or more than 0.99 . 


\subsection{Recombination dynamics under transient conditions}

Figure 6a compares charge carrier density decay for solar cells based on DR and AR active layers measured by the TRCE technique. Similar to the results obtained from the photocurrent versus voltage studies, the acceptor-rich devices have higher charge density initially. At the longer time scales, however, charge density in AR devices declines faster compared to the DR devices.

In Figure $6 \mathrm{~b}$ photovoltage decay measured for the DR and AR devices are compared. Initially, both devices show a similar photovoltage of around $0.77 \mathrm{~V}$, which is close to the open circuit potential values measured under steady state illumination conditions. The photovoltage decay of the DR devices features two distinguishable regimes $(<1 \mu \mathrm{s}$ and $>1 \mu \mathrm{s})$, while the photovoltage in the AR devices decreases monotonously over time. The measured photovoltage decay for each device depends on the charge density and the energetics (density of states (DOS)) of the charge transport sites near the contacts. Plotting the photovoltage versus charge density (Figure 7a), both obtained from transient measurements, suggests no major difference between the energy levels in AR and DR devices, i.e. the same charge density leads to similar open circuit potential in both devices. This suggests that the difference in photovoltage decays between AR and DR devices is related to the dynamics of charge carrier density decay at the electrodes.

Charge carrier bimolecular recombination lifetime $(\tau)$ can be calculated from charge carrier density decays over time as [32]:

$$
\tau=\frac{1}{\mathrm{n} \beta}=-\mathrm{n}\left(\frac{\mathrm{dn}}{\mathrm{dt}}\right)^{-1}
$$

where $n$ is electron (hole) density and $\beta$ is bimolecular recombination coefficient. The bimolecular recombination lifetime versus $V_{o c}$ plots suggests longer charge carrier lifetime in the AR devices in the $1 \mu$ s to $10 \mu$ s (corresponding to 0.7 to $0.6 V$ in Figure $6 \mathrm{~b}$ ) time window, which explains the larger photovoltage for AR devices. 

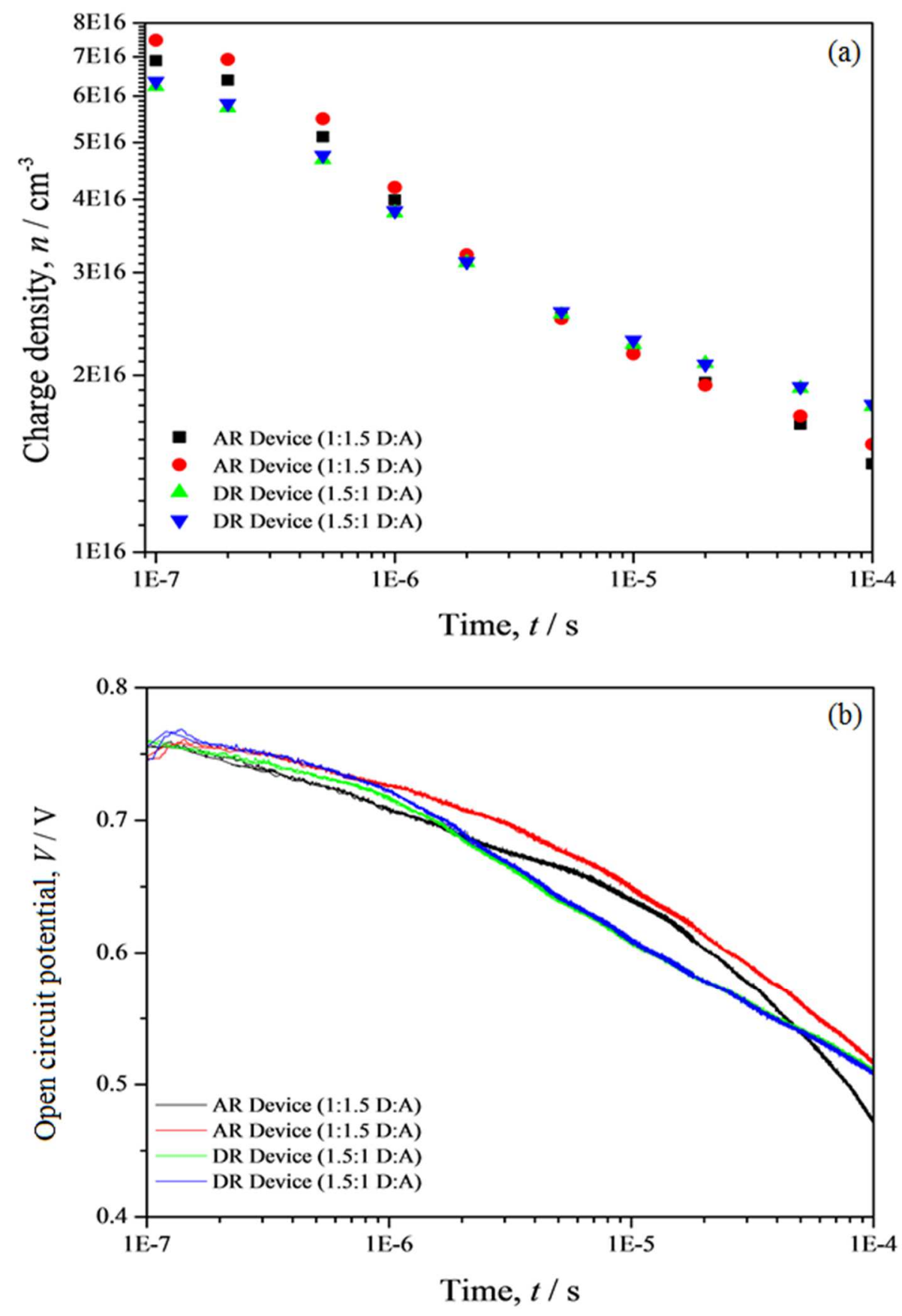

Figure 6. (a) Charge carrier density decay and (b) photovoltage decay over time of acceptor-rich (black and red) and donor-rich (green and blue) solar cell devices. 

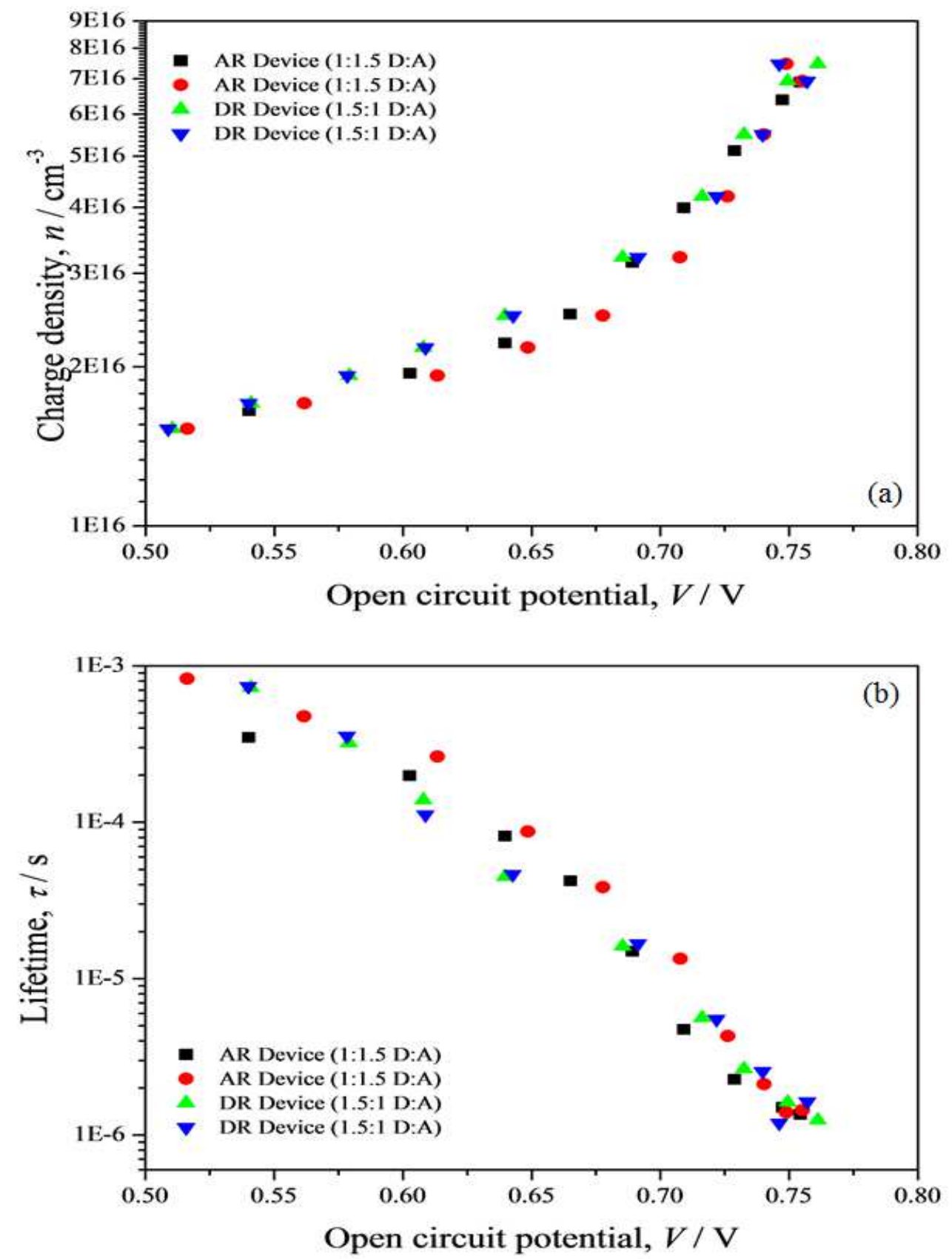

Figure 7. (a) Charge carrier density and (b) charge carrier lifetime versus open circuit potential of acceptor-rich (black and red) and donor-rich (green and blue) solar cell devices. 


\section{Discussion}

It is suggested that the presence of an injection/extraction barrier in the DR devices resulted in the S-curve behavior considering the analysis of $\mathrm{J}-\mathrm{V}$ curves, EQE, charge generation and collection, surface morphology and photovoltage decay measurements. To estimate the size of the extraction barrier, the photocurrent $J_{p h}$ versus $V_{\text {int }}$ curve (Figure $3 \mathrm{~b}$ ) of the DR device was re-plotted by adjusting $V_{B I}$ and by adding $2.8 \mathrm{~mA} \mathrm{~cm}^{-2}$ to the measured photocurrent (Figure 8 ). The added $J_{p h}$ was consistent with the differences in $J_{s c}$ and the EQE results and was also due to lower charge photo-generation in the DR devices as explained above. By adjusting the internal voltage by 0.32 $V$, a reasonably good overlap of the $J_{p h}$ versus $V_{i n t}$ of the two solar cells was obtained. This suggests that charge extraction is limited in the DR devices and that this is due to the lower internal field. The internal field is reduced due to a charge extraction barrier. Given that $V_{\text {int }}$ values of the DR devices is $0.2 V$ higher compared with $V_{\text {int }}$ of AR device, the additional barrier in the DR devices is approximately $0.12 \mathrm{~V}(0.32 \mathrm{~V}-0.2 \mathrm{~V})$.

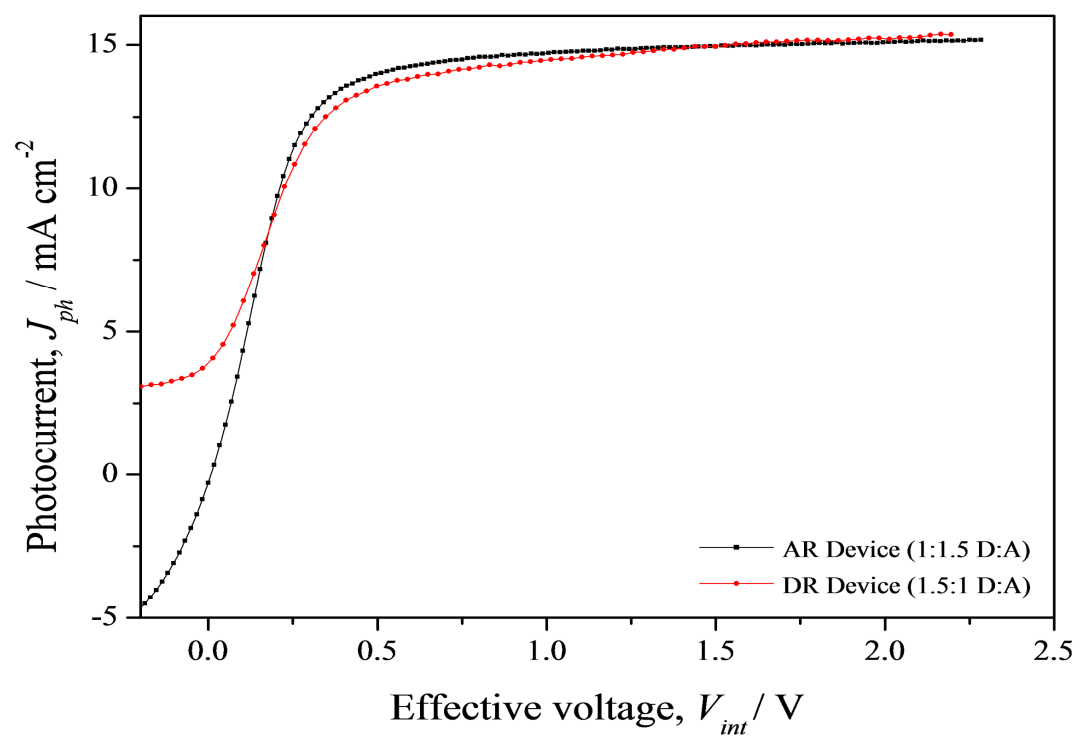

Figure 8. Photocurrent overlay of DR device to AR device by subtracting - $0.32 \mathrm{~V}$ from effective voltage and adding $2.8 \mathrm{~mA} \mathrm{~cm}^{-2}$ to current density. 
The energy barrier may arise from i) defects at the active layer/electrode interface, such as charge trap, low conductivity insulating layers or surface recombination; ii) changes to the active layer itself. To distinguish between two origins, a series of DR devices have been prepared with a modified electron extraction contact using $\mathrm{TiO}_{\mathrm{x}}$ and $\mathrm{ZnO}$ electron interfacial layers [14] (Table S3, Supplementary Information). All devices showed S-shaped current-voltage curves, associated with low fill factors. This and the strong dependency on the donor to acceptor ratio suggest that the origin of the extraction barrier is not related to the contact materials, but the active layers themselves. The surface morphological characteristics of the DR and AR devices, as revealed by AFM surface topography, do suggest changes in the domain size and surface roughness. Both of these properties could indicate changes at the top of the active layer films. An extraction barrier would be reasonably expected if a thin, donor-rich layer formed at the top of active layer due to for example the differences in the solubility of the donor/acceptor materials [28]. Such a donorrich layer in contact with the electron extracting aluminum contact would be detrimental to charge extraction. The extraction barrier would then originate from the voltage loss arising from the low electron conductivity (high electrical resistance) of the donor-rich surface region. Electrically, the donor-rich interfacial layer would manifest as a second diode in series to the bulk heterojunction, as illustrated in Figure 9a. Under steady state conditions, the current flowing through both diodes is the same, but depending on the resistance, the voltage drop is divided between the two diodes. By examining the current-voltage curves in Figure 2a the second diode (donor-rich layer) opens at a higher applied voltage (by $0.5 \mathrm{~V}$ ) compared to the first diode (bulk heterojunction) and generates only marginal photocurrent compared to the bulk heterojunction diode under illumination. This marginal, albeit non-zero photocurrent of the second diode is the reason for the slightly increased $V_{o c}$ and $V_{B I}$ in the current-voltage curves of the S-shaped DR devices. Due to the additional voltage 
expended to facilitate charge extraction through the second diode with diminished electron conduction, the internal voltage of the first diode (bulk heterojunction) is reduced and charge collection efficiency near the $V_{o c}$ conditions is diminished manifesting in a low FF. The 20\% lower $J_{s c}$ is attributed to the low charge generation yield in the donor-rich interfacial layer.

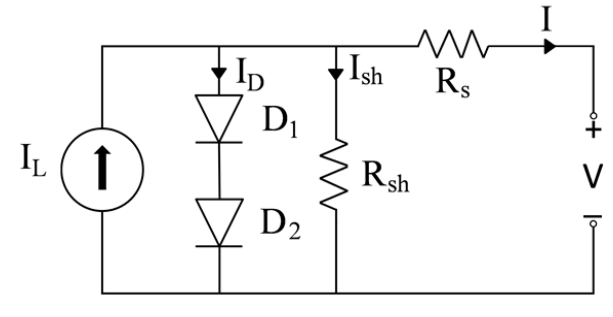

(a)

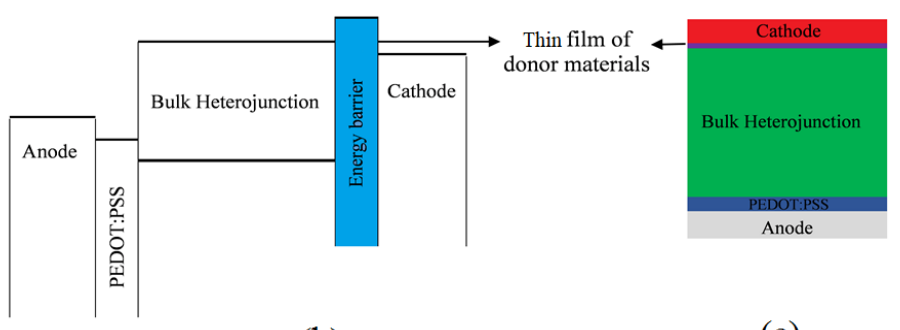

(b) (c)

Figure 9. (a) Equivalent circuit, (b) energy diagram and (c) schematic presentation of the DR devices.

Electron (hole) density $\left(n_{s c}\right)$ and charge carrier sweep-out time $\left(\tau_{s}\right)$ were also calculated, i.e. two electrical characteristics of the solar cell devices at or around short circuit conditions, using equations (3) and (4) respectively [29]:

$$
\begin{gathered}
\mathrm{J}_{\mathrm{ph}, \mathrm{sat}}=\mathrm{edG}_{\max }=2 \mathrm{en} \mathrm{n}_{\mathrm{sc}} \mu \frac{\mathrm{V}_{\text {int }}}{\mathrm{d}} \\
\tau_{\mathrm{s}}=\frac{\mathrm{d}^{2}}{2 \mu \mathrm{V}_{\mathrm{bi}}}
\end{gathered}
$$

where $\mu$ is mobility of charge carriers. The charge carrier mobility for both DR and AR devices was measured by photo-induced charge extraction with linearly increasing voltage (Photo-CELIV) technique and the results are shown in Table S4 (Supplementary Information). The calculated values for $n_{s c}$ and $\tau_{s}$ are shown in Table 2. Although both devices possess quite similar sweep-out time, the AR device has higher electron (hole) density at short circuit, indicating that the difference between acceptor-rich and donor-rich devices at short circuit conditions comes from the generation of charge carriers, otherwise, the electric field in both devices is strong enough to suppress any 
Table 2. Calculated values of the electron (hole) density and charge carrier sweep-out time at short circuit conditions for DR and AR devices.

$$
n_{s c}\left(\mathrm{~cm}^{-3}\right)
$$

\begin{tabular}{ccc}
\hline Donor-rich device & $1.7963 \times 10^{16}$ & $2.853 \times 10^{-6}$ \\
Acceptor-rich devices & $3.489 \times 10^{16}$ & $3.685 \times 10^{-6}$ \\
\hline
\end{tabular}

barrier and extract all charge carriers into respective electrodes.

Photo-CELIV curves (Figure S3 and Table S4, Supplementary Information) show only one extraction peak implying that charge carrier mobility is fairly balanced within active layer and both charge carriers possess similar mobility $\left(\sim 1.7\right.$ to $\left.2.1 \times 10^{-5} \mathrm{~cm}^{-2} \mathrm{~V}^{-1} \mathrm{~s}^{-1}\right)$ within experimental error. Therefore, the asymmetry between electron and hole mobility is not the main reason for the presence of S-shaped current-voltage behavior in DR devices. It must be noted that the photoCELIV technique relies upon the extraction of photo-generated charge carriers after a certain, adjustable delay time [32-35]. The fact that a difference in mobility between DR/AR devices was not observed, does not preclude the presence of a thin donor-rich layer with diminished electron mobility. Under the experimental conditions of photo-CELIV, due to small photo-generation in the donor-rich phase, transient charge extraction from this layer would not be visible. Under steady state conditions, on the other hand, electrons must be transported through this layer limiting the total current through the device.

Light intensity-dependency current-voltage results (Figure 5 and Supplementary Information) suggest similar $\alpha$ values for both devices, implying that bimolecular recombination is almost identical in the DR and AR devices at short circuit conditions and the difference in $J_{s c}$ is mainly due to the difference in charge generation in the devices as explained above. On the other 
hand, at open circuit conditions, the bimolecular recombination is prominent albeit the slope values are higher than $k T / e$ in both devices. The higher measured values than $k T / e$ could be attributed to the presence of trap states between the active layer and the cathode electrode (aluminum), which result in stronger dependency on the light intensity [30]. As such, the interface in acceptor-rich and donor-rich devices acts quite similar and the S-shaped current-voltage curve is not brought about by morphological defects (e.g. due to aluminum penetration to the active layer) or charge trapping at the interface.

These results are also confirmed by charge extraction, showing the similar dependence of $V_{o c}$ on charge density. The difference in $V_{o c}$ decays between DR an AR devices, the former showing a faster decay in the $10^{-6}$ to $10^{-4} \mathrm{~s}$ time region, could indicate a difference in charge carrier dynamics at the interfaces. The faster $V_{o c}$ decay could indicate the existence of a faster (transient) component of recombination near one of the contacts (the aluminum contact based on the discussion above is suggested), leading to a slightly shorter lifetime. Faster recombination in a donor-rich layer is feasible if electrons are localized in the scarce acceptor phase. However, while the difference in recombination kinetics measured by transient techniques supports the proposed existence of a donor-rich interfacial region, we think this effect is not large enough to explain the existence of the extraction barrier. While the above results are consistent, it would be advantageous to directly determine the lateral morphology including the chemical compositions of the bulk heterojunction, e.g. by using secondary ion mass spectrometry [36] or x-ray reflectivity measurements [37] as opposed to looking at only the bulk surface using AFM. This may be lead to deeper understanding of the S-curve physical origin, but it is outside the focus of this paper. 


\section{Conclusion}

In this study, we have shown that an S-shaped current-voltage curve appears in BHJ solar cells based on solution-processed small molecule $p$-DTS(FBTTh $)_{2}: \mathrm{PC}_{70} \mathrm{BM}$ with dependence on the donor-acceptor ratio. Investigation of photocurrent and charge collection probability as a function of effective voltage confirmed the reduction of charge carrier generation/collection particularly around open-circuit voltage (low effective voltage) in S-curve devices. The atomic force microscopy (AFM) study of the bulk film revealed that S-curve devices bulk was rougher with bigger grain size compared to normal device bulk. These results coupled with a $0.5 \mathrm{~V}$ shift of forward injection to higher potentials led to correlation between the appearance of the S-curve and an energy barrier stemming from the formation of a small molecule rich thin film on top of the active layer. As a result, the collection of electrons is hampered due to lower electron conductivity near the electron extracting contact, leading to an additional extraction barrier of $0.1 \mathrm{~V}$, a low fill factor and subsequently lower power conversion efficiency. The key to recovering normal device behavior is to increase the PCBM component. While recombination dynamics of charge carriers in both S-curve and normal solar cell devices are quite similar under steady-state conditions, employing transient techniques show that in the S-curve devices, charge carriers recombine slightly faster in the DR devices. Furthermore, charge carrier mobility of the devices, measured using the photo-CELIV technique, appeared to be in the same range. This indicated that mobility imbalance between hole and electron and the subsequent space charge effect cannot be the reason for the appearance of the S-shaped current density-voltage curve. 


\section{Acknowledgment}

A.A. acknowledge support from the Australian Research Council (ARC) and ARC Centre of Excellence for Electromaterials Science (ACES). A.A. acknowledges support from Australian National Fabrication Facility (ANFF). A.A. acknowledge Dr. Tian Zheng for the operation of AFM instrument.

\section{Supplementary Information}

Supplementary data associated with this article can be found in the online version at: 


\section{References}

[1] L. Lu, T. Zheng, Q. Wu, A.M. Schneider, D. Zhao, L. Yu, Recent Advances in Bulk Heterojunction Polymer Solar Cells, Chemical Reviews , 115 (2015) 12666-12731.

[2] Y. Lin, Y. Li, X. Zhan, Small Molecule Semiconductors for High-Efficiency Organic P0hotovoltaics, Chemical Society Reviews, 41 (2012) 4245-4272.

[3] S.D. Collins, N.A. Ran, M.C. Heiber, T.-Q. Nguyen, Small is Powerful: Recent Progress in Solution-Processed Small Molecule Solar Cells, Advanced Energy Materials, 10 (2017) 1602242.

[4] A. Mishra, P. Bäuerle, Small Molecule Organic Semiconductors on the Move: Promises for Future Solar Energy Technology, Angewandte Chemie International Edition, 51 (2012) 20202067.

[5] T.P. Osedach, T.L. Andrew, V. Bulović, Effect of Synthetic Accessibility on the Commercial Viability of Organic Photovoltaics, Energy and Environmental Science, 6 (2013) 711-718.

[6] W. Ni, M. Li, F. Liu, X. Wan, H. Feng, B. Kan, Q. Zhang, H. Zhang, Y. Chen, DithienosiloleBased Small-Molecule Organic Solar Cells with an Efficiency over 8\%: Investigation of the Relationship between the Molecular Structure and Photovoltaic Performance, Chemistry of Materials, 27 (2015) 6077-6084.

[7] B. Qiu, L. Xue, Y. Yang, H. Bin, Y. Zhang, C. Zhang, M. Xiao, K. Park, W. Morrison, Z. G. Zhang, Y. Li, All-Small-Molecule Nonfullerene Organic Solar Cells with High Fill Factor and High Efficiency over 10\%, Chemistry of Materials, 29 (2017) 7543-7553.

[8] H.G. Song, Y. J. Kim, J.S. Lee, Y. H. Kim, C. E. Park, S. K. Kwon, DithienobenzodithiopheneBased Small Molecule Organic Solar Cells with over 7\% Efficiency via Additive- and ThermalAnnealing-Free Processing, Advanced Materials, 8 (2016) 34353-34359. 
[9] Q. Zhang, B. Kan, F. Liu, G. Long, X. Wan, X. Chen, Y. Zuo, W. Ni, H. Zhang, M. Li, Z. Hu, F. Huang, Y. Cao, Z. Liang, M. Zhang, T.P. Russell, Y. Chen, Small-molecule Solar Cells with Efficiency Over 9\%, Nature Photonics, 9 (2014) 35.

[10] A.K.K. Kyaw, D.H. Wang, C. Luo, Y. Cao, T.-Q. Nguyen, G.C. Bazan, A.J. Heeger, Effects of Solvent Additives on Morphology, Charge Generation, Transport, and Recombination in Solution-Processed Small-Molecule Solar Cells, Advanced Energy Materials, 4 (2014) 1301469n/a.

[11] J.A. Love, C.M. Proctor, J. Liu, C.J. Takacs, A. Sharenko, T.S. van der Poll, A.J. Heeger, G.C. Bazan, T.-Q. Nguyen, Film Morphology of High Efficiency Solution-Processed SmallMolecule Solar Cells, Advanced Functional Materials, 23 (2013) 5019-5026.

[12] S. Mukherjee, C.M. Proctor, J.R. Tumbleston, G.C. Bazan, T.-Q. Nguyen, H. Ade, Importance of Domain Purity and Molecular Packing in Efficient Solution-Processed Small-Molecule Solar Cells, Advanced Materials, 27 (2015) 1105-1111.

[13] P. Zalar, M. Kuik, N.A. Ran, J.A. Love, T.-Q. Nguyen, Effects of Processing Conditions on the Recombination Reduction in Small Molecule Bulk Heterojunction Solar Cells, Advanced Energy Materials, 4 (2014) 1400438-n/a.

[14] A.K.K. Kyaw, D.H. Wang, D. Wynands, J. Zhang, T.-Q. Nguyen, G.C. Bazan, A.J. Heeger, Improved Light Harvesting and Improved Efficiency by Insertion of an Optical Spacer $(\mathrm{ZnO})$ in Solution-Processed Small-Molecule Solar Cells, Nano Letters, 13 (2013) 3796-3801.

[15] A. Orimo, K. Masuda, S. Honda, H. Benten, S. Ito, H. Ohkita, H. Tsuji, Surface segregation at the aluminum interface of poly(3-hexylthiophene)/fullerene solar cells, Applied Physics Letters, 96 (2010) 043305. 
[16] B. Tremolet de Villers, C.J. Tassone, S.H. Tolbert, B.J. Schwartz, Improving the Reproducibility of P3HT:PCBM Solar Cells by Controlling the PCBM/Cathode Interface, The Journal of Physical Chemistry C, 113 (2009) 18978-18982.

[17] D. Gupta, M. Bag, K.S. Narayan, Correlating reduced fill factor in polymer solar cells to contact effects, Applied Physics Letters, 92 (2008) 093301.

[18] H. Jin, M. Tuomikoski, J. Hiltunen, P. Kopola, A. Maaninen, F. Pino, Polymer-Electrode Interfacial Effect on Photovoltaic Performances in Poly(3-hexylthiophene):Phenyl-C61-butyric Acid Methyl Ester Based Solar Cells, The Journal of Physical Chemistry C, 113 (2009) 1680716810.

[19] A. Kumar, S. Sista, Y. Yang, Dipole induced anomalous S-shape I-V curves in polymer solar cells, Journal of Applied Physics, 105 (2009) 094512.

[20] W. Tress, S. Corvers, K. Leo, M. Riede, Investigation of Driving Forces for Charge Extraction in Organic Solar Cells: Transient Photocurrent Measurements on Solar Cells Showing S-Shaped Current-Voltage Characteristics, Advanced Energy Materials, 3 (2013) 873-880.

[21] W. Tress, K. Leo, M. Riede, Influence of Hole-Transport Layers and Donor Materials on Open-Circuit Voltage and Shape of I-V Curves of Organic Solar Cells, Advanced Functional Materials, 21 (2011) 2140-2149.

[22] J. Wagner, M. Gruber, A. Wilke, Y. Tanaka, K. Topczak, A. Steindamm, U. Hörmann, A. Opitz, Y. Nakayama, H. Ishii, J. Pflaum, N. Koch, W. Brütting, Identification of different origins for s-shaped current voltage characteristics in planar heterojunction organic solar cells, Journal of Applied Physics, 111 (2012) 054509. 
[23] W. Tress, A. Petrich, M. Hummert, M. Hein, K. Leo, M. Riede, Imbalanced mobilities causing S-shaped IV curves in planar heterojunction organic solar cells, Applied Physics Letters, 98 (2011) 063301.

[24] B.Y. Finck, B.J. Schwartz, Understanding the origin of the S-curve in conjugated polymer/fullerene photovoltaics from drift-diffusion simulations, Applied Physics Letters, 103 (2013) 053306.

[25] B. Qi, J. Wang, Fill factor in organic solar cells, Physical Chemistry Chemical Physics, 15 (2013) 8972-8982.

[26] A. Wagenpfahl, D. Rauh, M. Binder, C. Deibel, V. Dyakonov, S-shaped current-voltage characteristics of organic solar devices, Physical Review B, 82 (2010) 115306.

[27] J.C. Wang, X.C. Ren, S.Q. Shi, C.W. Leung, P.K.L. Chan, Charge accumulation induced Sshape J-V curves in bilayer heterojunction organic solar cells, Organic Electronics, 12 (2011) 880885.

[28] J.A. Love, S.-H. Chou, Y. Huang, G.C. Bazan, T.-Q. Nguyen, Effects of solvent additive on "s-shaped" curves in solution-processed small molecule solar cells, Beilstein Journal of Organic Chemistry, 12 (2016) 2543-2555.

[29] S.R. Cowan, A. Roy, A.J. Heeger, Recombination in polymer-fullerene bulk heterojunction solar cells, Physical Review B, 82 (2010) 245207.

[30] A.K.K. Kyaw, D.H. Wang, V. Gupta, W.L. Leong, L. Ke, G.C. Bazan, A.J. Heeger, Intensity Dependence of Current-Voltage Characteristics and Recombination in High-Efficiency SolutionProcessed Small-Molecule Solar Cells, ACS Nano, 7 (2013) 4569-4577. 
[31] L.J.A. Koster, V.D. Mihailetchi, H. Xie, P.W.M. Blom, Origin of the light intensity dependence of the short-circuit current of polymer/fullerene solar cells, Applied Physics Letters, 87 (2005) 203502.

[32] T.M. Clarke, C. Lungenschmied, J. Peet, N. Drolet, A.J. Mozer, A Comparison of Five Experimental Techniques to Measure Charge Carrier Lifetime in Polymer/Fullerene Solar Cells, Advanced Energy Materials, 5 (2015) 1401345-n/a.

[33] T.M. Clarke, J. Peet, A. Nattestad, N. Drolet, G. Dennler, C. Lungenschmied, M. Leclerc, A.J. Mozer, Charge carrier mobility, bimolecular recombination and trapping in polycarbazole copolymer:fullerene (PCDTBT:PCBM) bulk heterojunction solar cells, Organic Electronics, 13 (2012) 2639-2646.

[34] A.J. Mozer, G. Dennler, N.S. Sariciftci, M. Westerling, A. Pivrikas, R. Österbacka, G. Juška, Time-dependent mobility and recombination of the photoinduced charge carriers in conjugated polymer/fullerene bulk heterojunction solar cells, Physical Review B, 72 (2005) 035217.

[35] A.J. Mozer, N.S. Sariciftci, A. Pivrikas, R. Österbacka, G. Juška, L. Brassat, H. Bässler, Charge carrier mobility in regioregular poly(3-hexylthiophene) probed by transient conductivity techniques: A comparative study, Physical Review B, 71 (2005) 035214.

[36] A. Franquet, T. Conard, E. Voroshazi, C. Poleunis, D. Cheyns, W. Vandervorst, Characterization of organic solar cell materials by G-SIMS, Surface and Interface Analysis, 45 (2013) 430-433.

[37] B. Paci, A. Generosi, V.R. Albertini, P. Perfetti, R.d. Bettignies, M. Firon, J. Leroy, C. Sentein, In situ energy dispersive x-ray reflectometry measurements on organic solar cells upon working, Applied Physics Letters, 87 (2005) 194110. 